\title{
How to Regulate the DuE DILIGENCE DUTIES OF OFFICERS UNDER THE HEALTH AND SAFETY AT WORK ACT 2015
}

\author{
Nadia Dabee*
}

To date, no enforcement activity against officers under the Health and Safety at Work Act 2015 (HSWA) has been reported and methods to achieve compliance also appear to be underdeveloped. In addition to there being no prosecutions against officers for breach of their due diligence duties, there are also no formalised regulatory structures to help officers "self-regulate" effectively in order to comply with their due diligence duties. Instead, it appears that officers have been left mostly to regulate their own behaviour with some guidance from WorkSafe. This leaves a gap in the regulatory landscape of workplace health and safety in New Zealand. Opportunities for developing a unique regulatory structure geared towards regulating the due diligence duties become evident upon an examination of some of the literature on regulation. These opportunities are presented here.

\section{INTRODUCTION}

The Health and Safety at Work Act 2015 (HSWA) imposes due diligence duties on officers so that they can ensure the compliance of the person conducting a business or undertaking (PCBU) with their duties of care under the Act. ${ }^{1}$ To date, there have been no prosecutions or enforceable undertakings taken against officers directly. The regulatory guidance on WorkSafe's website is general and may not be easily adopted by businesses without expert advice. ${ }^{2}$

There appears to be a regulatory gap in New Zealand when it comes to the regulation of the due diligence duties. There are vast amounts of literature that show the correlation between good work

* Lecturer and PhD Candidate, Commercial Law Department, Business School, University of Auckland.

1 Health and Safety at Work Act 2015 [HSWA], s 44. See s 17 for a definition of "person conducting a business or undertaking" or "PCBU".

2 Institute of Directors and WorkSafe New Zealand Health and Safety Guide: Good Governance for Directors (March 2016) at 3. These guidelines highlight the important aspects of "due diligence" and how to implement them. 
health and safety (WHS) management and improved safety outcomes. ${ }^{3}$ Missing out on the opportunity to not just enforce, but to ensure compliance of the due diligence means missing out on an opportunity for New Zealand to make significant improvements in WHS.

Part II provides the background to the reasons for imposing due diligence duties on officers. Part III analyses the literature on the current regulatory models being used in the regulation of the due diligence duties. This analysis reveals several gaping holes in the regulation of these duties, which then leads to an opportunity to better regulate. A focus on compliance rather than on punishment is preferable, as punishment may lead to defensive behaviour which stultifies the process of improving WHS. A key component in any regulatory system is the accountability of the regulators. This aspect is looked at in Part IV. This article then concludes with a sketch of what a regulatory structure for the due diligence duties of officers could look like. This suggestion is by no means intended to be the final word on the matter. This article merely aims to start the discussion on how to effectively regulate the due diligence duties of officers.

\section{BACKGROUND}

On 19 November 2010, the Pike River Mine exploded and 29 miners died. ${ }^{4}$ The perception was that the directors of the mine did not take their health and safety duties towards the workers seriously. ${ }^{5}$

A Royal Commission investigated the accident and made two specific recommendations in relation to directors: ${ }^{6}$

- $\quad$ they should have statutory responsibilities to reflect their "governance responsibilities"; 7

- they should "rigorously review and monitor their organisation's compliance with health and safety law and best practice". ${ }^{8}$

3 See for example Beatriz Fernández-Muñiz, José Manuel Montes-Peón and Camilo José Vázquez-Ordás "Safety culture: Analysis of the causal relationships between its key dimensions" (2007) 38 Journal of Safety Research 627; Sharon Clarke, Sara Guediri and Allan Lee "Leadership and Safety: A Self-Regulation and Social Learning Perspective" in E Kevin Kelloway, Karina Nielsen and Jennifer K Dimoff (eds) Leading to Occupational Health and Safety: How Leadership Behaviours Impact Organizational Safety and Well-Being (John Wiley and Sons, New Jersey, 2017) 9 at 27; Sharon Clarke and Ian Taylor "Reducing workplace accidents through the use of leadership interventions: a quasi-experimental field study" (2018) 121 Accident Analysis and Prevention 314; and Bruce J Avolio and others "A meta-analytic review of leadership impact research: Experimental and quasi-experimental studies" (2009) 20 The Leadership Quarterly 764.

4 See Royal Commission on the Pike River Coal Mine Tragedy: Volume 1+ Overview (October 2012) at 3

5 At 18.

6 At 3.

7 At 37 .

$8 \quad$ At 37 . 
An independent taskforce then examined the state of WHS in New Zealand. One of the key reasons why New Zealand had a poor WHS record was found to be a lack of responsibility by heads of organisations. ${ }^{9}$ Business leaders had "generally low health and safety capabilities", lacked training, support and expertise. ${ }^{10}$ Businesses lacked the capacity to deal with WHS matters because of a lack of access to trained WHS experts. ${ }^{11}$ This then created a barrier to leaders' ability to respond to "new and emerging risks". ${ }^{12}$

Poor WHS leadership was a result of: a lack of accountability; "marginalisation" of WHS responsibilities and delegation of those responsibilities to WHS managers; commercial pressures; low awareness of WHS issues; and a gap between the boardroom and the "coalface". ${ }^{13}$ A failure to engage with unions was also singled out as a reason for New Zealand's poor safety records. ${ }^{14}$

In response, the Government enacted the HSWA, which is based on the Australian Model, the Workplace Health and Safety Act 2011 (MWHSA). An "officer" is defined as a director of a company, or a partner in a partnership or a person who is able to "exercise significant influence over the management" of the PCBU. ${ }^{15}$ To ensure the compliance of the PCBU, the due diligence duties require officers to: ${ }^{16}$

(4) $\quad \ldots$ tak $[\mathrm{e}]$ reasonable steps-

(a) to acquire, and keep up to date, knowledge of work health and safety matters; and

(b) to gain an understanding of the nature of the operations of the business or undertaking of the PCBU and generally of the hazards and risks associated with those operations; and

(c) to ensure that the PCBU has available for use, and uses, appropriate resources and processes to eliminate or minimise risks to health and safety from work carried out as part of the conduct of the business or undertaking; and

(d) to ensure that the PCBU has appropriate processes for receiving and considering information regarding incidents, hazards, and risks and for responding in a timely way to that information; and

9 The Report of the Independent Taskforce on Workplace Health \& Safety (April 2013) at [105]-[106] and [108].

10 At [110].

11 At [110].

12 At [145].

13 At [112].

14 At [111].

15 HSWA, s 18.

16 HSWA, s 44. 
(e) to ensure that the PCBU has, and implements, processes for complying with any duty or obligation of the PCBU under this Act; and

(f) to verify the provision and use of the resources and processes referred to in paragraphs (c) to $(e)$.

The HSWA is based on the Robens model. The Robens Report had recommended a statute that was "enabling" in nature, with details to be left to "subordinate instruments". ${ }^{17}$ In line with this, the HSWA states the main duties of officers and PCBUs, ${ }^{18}$ with regulations setting out more specific rules. ${ }^{19}$

The Robens Report did not actually contemplate that officers would be personally liable for the failures of their organisation. Instead, the assumption appeared to be that employers would come to the table and negotiate with workers to ensure safety. ${ }^{20}$ In spite of the fact that the Robens Report did not recommend that personal liability be placed on officers, Parliament decided to do so and followed the Australian example in that regard. Presumably, one of the sub-aims of imposing due diligence duties is an attempt to ensure, through personal liability, that the employer (the PCBU) does come to the table to negotiate with workers in a way that will improve WHS culture. ${ }^{21}$

According to Steve Tombs and David Whyte, if any of the three branches of the tripartite arrangement are unable to function according to the plan laid out in Robens model, then the regulation of occupational health and safety (OHS) and WHS becomes "necessarily vulnerable to degradation". ${ }^{22}$ Thus, the inability of workers to come to the table, ${ }^{23}$ and the seeming reluctance of inspectors to enforce the duties, may have led to a regulatory "degradation". ${ }^{24}$

17 Committee on Safety and Health at Work Safety and Health at Work: Report of the Committee 1970-1972 (Cmnd 5034, June 1972) [Robens Report] at [127].

18 At [129].

19 At [136].

20 Robert Baldwin Rules and Government (Clarendon Press, Oxford, 1995) at 127.

21 HSWA, s 44(4)(d); Robin Stewart-Crompton, Stephanie Mayman and Barry Sherriff National Review into Model Occupational Health and Safety Laws: First Report to the Workplace Relations Ministers' Council (October 2008) at [8.1], [8.5] and [8.3]; and Robin Stewart-Crompton, Stephanie Mayman and Barry Sherriff National Review into Model Occupational Health and Safety Laws: Second Report to the Workplace Relations Ministers' Council (January 2009) at [25.170] and [36.13].

22 Steve Tombs and David Whyte "A Deadly Consensus: Worker Safety and Regulatory Degradation under New Labour" (2010) 50 Brit J Criminol 46 at 47 (emphasis omitted).

23 Nadia Dabee "Incoherence in the Health and Safety at Work Act 2015: Limitations on the Right to Worker Representation" (2018) 28 NZULR 102.

24 Tombs and Whyte above $\mathrm{n} 22$, at 47. 
Perhaps we are seeing a lack of formal enforcement against officers in New Zealand because the workers are unable to participate in the regulation of the due diligence duties or to push for these duties to be enforced. Although these hypotheses remain to be tested.

Furthermore, the current enforcement model of WHS duties in New Zealand, including officers' due diligence duties, is based on the responsive regulation model (discussed further below). ${ }^{25}$ Tombs and Whyte argue that responsive regulation is no more than a way to thinly disguise deregulatory tendencies. ${ }^{26}$ As responsive regulation is a compromise between regulation and deregulation, Tombs and Whyte argue that responsive regulation "contains the seeds of its own perennial degradation". ${ }^{27}$

If one wants to be cynical, it is possible to argue that the lack of enforcement against officers is the result of the state employing a "hands off" neo-liberal approach to the regulation of capital. ${ }^{28}$ One possible reason for this could be the fact that the regulation of WHS may be seen as "quasi-criminal" by some regulatees, or lacking in moral seriousness. ${ }^{29}$ If a law is seen to lack "moral seriousness", then the regulatees may feel that being punished by regulators is unfair. ${ }^{30}$ Pressure from regulatees (officers) on the government may have caused the regulator to enforce the law "softly", and thus, in Christine Parker's words, "ineffectively". ${ }^{31}$ Or it may simply be that WorkSafe does not currently have the capacity to prosecute officers. Whatever the reason may be, a gap exists in the regulatory landscape of the due diligence duties. The discussion below addresses both issues: pushing against neo-liberal trends and building capacity for compliance.

25 See WorkSafe New Zealand Enforcement: Regulatory Function Policy (August 2017); and SafeWork Australia National Compliance and Enforcement Policy (September 2011) at 6. See also Steve Tombs and David Whyte "Transcending the deregulation debate? Regulation, risk and the enforcement of health and safety law in the UK" (2013) 7 Regulation \& Governance 61 at 66. The authors argue that occupational health and safety (OHS) regulators have adopted responsive regulation.

26 Tombs and Whyte, above n 25, at 62.

27 At 62 .

28 See generally Kit Carson and Richard Johnstone "The Dupes of Hazard: Occupational Health and Safety and the Victorian Sanctions Debate" (1990) 26 ANZJS 126.

29 At 129.

30 Christine Parker "The 'Compliance' Trap: The Moral Message in Responsive Regulatory Enforcement Law" (2006) 40 L \& Soc'y Rev 591 at 602.

31 At 591 


\section{AN ANALYSIS OF THE REGULATION OF THE DUE DILIGENCE DUTIES}

\section{A The Trend Towards "Decentring"}

The current regulatory model governing WHS in New Zealand is more closely aligned with what has been described as a "decentred model". ${ }^{32}$ "Decentring" usually refers to the normative assertion that governments should not have a monopoly on regulation. ${ }^{33}$ The term also refers to the positive assertion that governments do not, in practice, have a monopoly on regulation as "large organizations, collective associations, technical committees [and] professions" sometimes regulate themselves without any form of government intervention. ${ }^{34}$

Decentring regulation also involves the admission that governments are not omnipotent and, more often than not, are acted upon rather than being actors in their own right. ${ }^{35}$ Decentring also refers to the removal of the government from the "conceptual centre of society", or the "de-apexing" of the government from the hierarchy. ${ }^{36}$

Julia Black proposes that the trend towards decentred regulation is the result of several factors and/or assumptions: ${ }^{37}$

(1) complexity that results from the interaction of actors and from factors both known and unknown;

(2) the fact that the regulatee may have more knowledge about their industry than the regulator, but also that a single actor cannot have all the knowledge needed to solve a complex problem and that each institution has its own views of the problem;

(3) the exercise of power and control does not rest solely with the regulator but is distributed among various actors;

(4) social actors are autonomous and will continue to follow the rules even in the absence of regulatory intervention;

(5) each actor is limited in their actions by their own knowledge and by the actions of other actors;

32 Donald Feaver and Benedict Sheehy "Designing Effective Regulations: A Positive Theory" (2015) 38 UNSWLJ 961 at 969.

33 Julia Black "Decentering Regulation: Understanding the Role of Regulation and Self-Regulation in a 'PostRegulatory' World" (2001) CLP 103.

34 At 103.

35 At 104 .

36 At 104

37 At $106-110$ 
(6) interactions between social actors and the government are both complex and interdependent and all these variables add up to "obscure" rather than "illuminate" public policy. ${ }^{38}$ Unintended, but not necessarily adverse consequences can result, and a possible way to mitigate unintended consequences is to use a mix of regulatory instruments. ${ }^{39}$ The design of the regulation also depends on context. ${ }^{40}$

(7) the fact that regulation can happen without formal authority. The interaction between various actors leads to the regulation of the various actors' actions, and the public/private distinction can become blurred.

Several of these factors are present in the regulation of WHS. Complexity is present in many workplaces, and the way people and events interact with each other can often produce unexpected results that may culminate into an accident. ${ }^{41}$

The fact that the regulatee has more knowledge of their business than the regulator has been one of the keystones of the modern WHS legislation. ${ }^{42}$ Regulatees have the ability to decide how to comply with the legislation and how to implement approved codes of practice or develop their own methods of complying. ${ }^{43}$

The assumption that most businesses want to comply and will do so even without regulatory intervention is contentious. Some academics believe duty-holders will maximise their profits and prefer to not implement safety procedures if it is cheaper than doing so. ${ }^{44}$ Others believe that dutyholders will choose compliance over non-compliance because of the inherent willingness to be on the right side of the law. ${ }^{45}$ Having said that, each actor is limited in their locus of control, especially workers who often do not have a say in how resources are distributed.

In a perfect Coasian world if the least-cost avoider is liable (the person who can prevent the injury at the least cost), they will act to prevent the accident if doing so is cheaper than the cost of the accident

38 At 113 .

39 At 113

40 At 113

41 See generally Erik Hollnagel Safety-I and Safety-II: The Past and Future of Safety Management (Ashgate Publishing, Farnham (UK), 2014); and James Reason Managing the Risks of Organizational Accidents (Routledge, Abingdon-on-Thames (UK), 2016).

42 Robens Report, above n 17, at [79].

43 At [353].

44 See Robert A Kagan, Neil Gunningham and Dorothy Thornton "Fear, Duty, and Regulatory Compliance: Lessons from Three Research Projects" in Christine Parker and Vibeke Nielson (eds) Explaining Compliance: Business Responses to Regulation (Edward Elgar Publishing, Massachusetts, 2011) 37 at 40.

45 At 41 . 
itself. ${ }^{46}$ Transaction costs are however not negligible in practice, as employees often cannot estimate the risk of a job or indeed negotiate a wage premium for a risky job. The cost to employers is determined by the extent to which compensation laws impose liability on employers. The cost to employees is usually pain, lost income and medical bills. ${ }^{47}$ Workers are also constrained in how well they can perform by how much training they get and the level of support they can get from management. ${ }^{48}$

Various actors can act on the government in a way that muddles policymaking. An example of this occurring is the lobbying against increased workers' rights to representation. ${ }^{49}$ The extent to which lobbying (if any) has played a role in WorkSafe's decision to not prosecute officers remains unknown.

The current situation in New Zealand is that enforcement powers rest with WorkSafe which has substantial powers. ${ }^{50}$ Organisations are also called upon to manage their own risks. WorkSafe's enforcement policy states that it will engage with regulatees so that it can "best identify and manage risks". 51

WorkSafe is able to issue guidance on how officers should discharge their duties. ${ }^{52}$ While inspectors can perform administrative and enforcement functions, ${ }^{53}$ currently there are not enough inspections occurring for inspectors to develop a relationship with officers to significantly improve WHS. ${ }^{54}$

46 Richard J Butler and John D Worrall "Wage and Injury Response to Shifts in Workplace Liability" (2008) 61 Indus \& Lab Rel Rev 181 at 182.

47 James R Chelius "The Influence of Workers' Compensation on Safety Incentives" (1982) 35 Indus \& Lab Rel Rev 235 at 236.

48 See generally Avolio and others, above n 3, at 777.

49 Dabee, above n 23.

50 See WorkSafe New Zealand Act 2013.

51 WorkSafe New Zealand, above n 25, at 4.

52 WorkSafe New Zealand WorkSafe Position: Officers' due diligence (February 2019).

53 See HSWA, sub-pt 10.

54 WorkSafe New Zealand Annual Report 2018/2019 (June 2019) at 22. There are 251 inspectors for 546,740 businesses: Statistics New Zealand "New Zealand business demography statistics: At February 2019" (25 October 2019 <www.stats.govt.nz/information-releases>. 


\section{B Responsive Regulation}

Responsive regulation attempts to reach a compromise between deregulation and state intervention. ${ }^{55}$ The premise appears to be simple: the regulator rewards those who self-regulate properly by not intervening, ${ }^{56}$ and intervenes when self-regulation fails by deploying the "big guns". 57

The theory underlying responsive regulation posits that, when WHS actors act as good citizens who obey the law, the regulator works cooperatively with the duty-holder to obtain compliance by providing advice and encouragement. ${ }^{58}$ The regulator is in compliance mode, acting as a "benign big gun". ${ }^{59}$ At other times, WHS actors may act as economically rational persons who favour their own self-interest and choose not to obey the strict letter of the law because non-compliance, even if punished, is cheaper than compliance. ${ }^{60}$ The regulator then enters "deterrence mode", and wields the threat of possible escalating punishments under the law to obtain compliance. ${ }^{61}$ If the threat does not work, then punishment is imposed. ${ }^{62}$

Thus, in theory at least, an officer who is compliant would get advice and support from the regulator, and an officer who persistently fails to exercise due diligence would face a sanction, the severity of which would depend on the how persistent and/or egregious the officer's breaches were. The main problem in New Zealand, however, is that there appears to have been no enforcement actions taken against officers yet. However, there is some evidence of officers changing their behaviour to comply with their due diligence duties. ${ }^{63}$

55 Ian Ayres and John Braithwaite Responsive Regulation: Transcending the Deregulation Debate (Oxford University Press, Oxford, 1992) at 3. For a further discussion on the compromise between state regulation and deregulation see Christine Parker "Twenty years of responsive regulation: An appreciation and appraisal" (2013) 7 Regulation \& Governance 2 at 2-3.

56 See the definition for self-regulation in Part III(F) below.

57 Ayres and Braithwaite, above n 55, at 4.

58 At 35

59 At 19.

60 At 36 .

61 At 38 .

62 At 38

63 See for example Department of Corrections Annual Report 2018/2019 (June 2019) at 24. The Department of Corrections won the Best Board-Level Engagement Award at the annual Safeguard Health and Safety Awards. 
Under the responsive regulation theory, the compliance and enforcement mechanisms can be illustrated diagrammatically using an enforcement pyramid (see Figure 1 below). ${ }^{64}$ The pyramid represents the "interpersonal relationships" of all the actors involved and is thus very appealing to researchers and regulatory practitioners alike. ${ }^{65}$

The base of the pyramid is the widest part where most of the enforcement activity takes place and where the regulator encourages voluntary compliance by the duty-holder. The regulator appeals to the duty-holder's innate sense of wanting to "do the right thing" and to obey the law. ${ }^{66}$ If the WHS actor does not comply when the regulator "plays nice", the regulator will then start using more deterrencebased techniques to obtain compliance and "escalate" up the enforcement pyramid by gradually using more punitive sanctions. ${ }^{67}$

Ayres and Braithwaite argue that regulators are "more able to speak softly when they carry big sticks" and have a hierarchy of lesser sanctions available to them. ${ }^{68}$ The notion of carrying a "big stick" is related to the deterrability of the regulatee. Elsewhere, Braithwaite argues that white collar workers (such as officers) are more deterrable because they would have more to lose, such as "status, respectability, money, a job, a comfortable home and family life". ${ }^{69}$ Braithwaite states that obtaining accurate data sets to understand white collar crime is difficult as executives will probably not answer questions about their own criminal behaviour, and most offences are either not detected or not recorded. ${ }^{70}$

William Chambliss was able to look at some of the data on white collar crime. ${ }^{71} \mathrm{He}$ found that white collar workers feared punishment especially as it was seen to be "dishonourable". ${ }^{72}$ White collar workers also appeared to be less committed to "crime as a way of life", but rather committed crimes when it helped them achieve objectives they were pursuing. ${ }^{73}$ This aligns with Braithwaite's

64 Ayres and Braithwaite, above n 55, at 35. See also Peter Mascini "Why was the enforcement pyramid so influential? And what price was paid?" (2013) 7 Regulation \& Governance 48.

65 Parker, above n 55, at 4.

66 Ayres and Braithwaite, above n 55, at 25.

67 At 36 .

68 At 19.

69 John Braithwaite "White Collar Crime" (1985) 11 Ann Rev of Sociol 1 at 16.

70 At 5

71 William J Chambliss "Types of Deviance and the Effectiveness of Legal Sanctions" [1967] Wis L Rev 703 at 709 .

72 At 709

73 At 712-713. 
suggestion that profit may not be the sole motivation for white collar crime. ${ }^{74}$ Pressures to meet targets such as government imposed quotas, or bending to the will of professionals they cater to, may provide other motivations. ${ }^{75} \mathrm{He}$ argues that the push toward white collar crime may be caused by whatever goals are emphasised to organisations. ${ }^{76}$

In another empirical study, Stanton Wheeler and others concluded that the motivation to commit white collar crime tended to arise under two situations: firstly, when the company was under financial pressure and they were at risk of losing their lifestyle; and secondly, in an ironical twist, crimes were committed out of a fear of failure of losing what they had worked hard for. ${ }^{77}$

It appears then, that economic pressures and targets imposed on officers may influence their decisions, even if there is a significant possible punishment. There are three criminal offences in the HSWA (highlighted below). Health and safety representatives can also issue provisional improvement notices. $^{78}$

Figure 1: Reproduction of Ayers and Braithwaite's Enforcement Pyramid. ${ }^{79}$

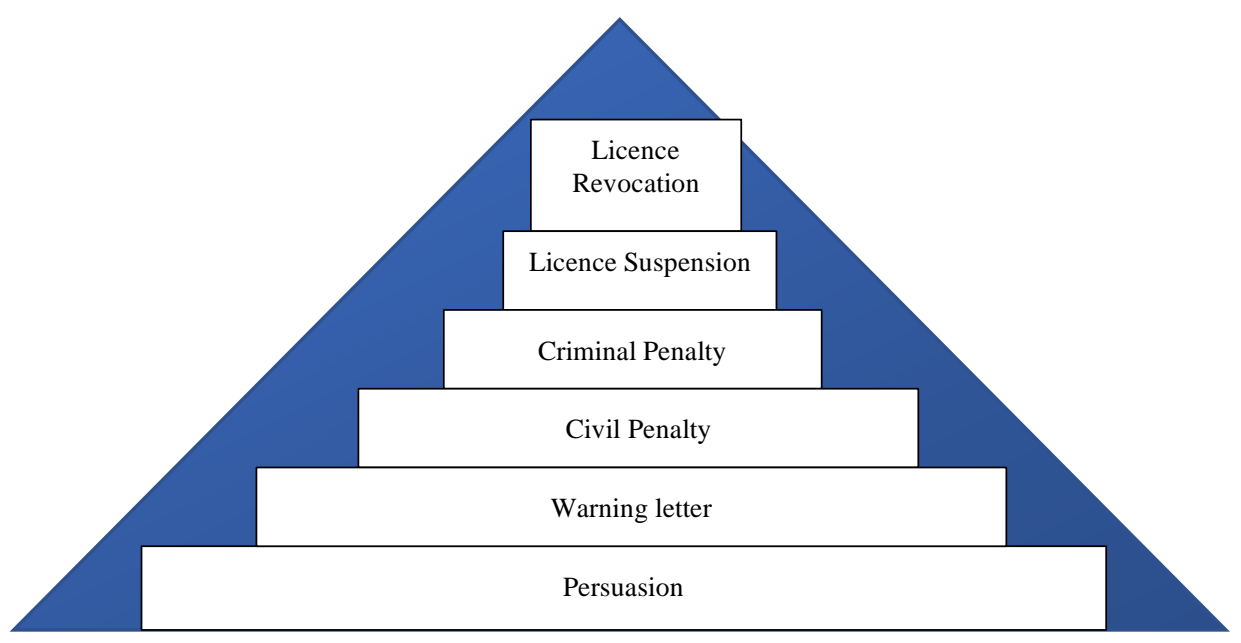

74 Braithwaite, above $\mathrm{n} 69$, at 8 .

75 At 8 .

76 At 8 .

77 Stanton Wheeler and others "White Collar Crimes and Criminals" (1988) 25 Am Crim L Rev 331 at 354. The study was carried out in the United States. The authors selected eight specific federal level statutory offences involving financial crime. The study only looked at convicted offenders, but the authors took the view that non-apprehended offenders may hold the same views as those who were convicted.

78 HSWA, s 69.

79 Ayres and Braithwaite, above n 55, at 36. 
Escalating up the pyramid, officers could be issued with warnings such as provisional improvement notices. ${ }^{80}$ The regulator can also issue improvement ${ }^{81}$ and prohibition ${ }^{82}$ notices. As an alternative to prosecution, the regulator may accept an enforceable undertaking. ${ }^{83}$

Escalating further up the pyramid is the ability to impose civil penalties. The imposition of a civil penalty does not give individuals the right to sue the officer. Rather, it is the imposition of a penalty on a civil balance of probabilities with there being no need to prove intention or recklessness. Civil pecuniary penalties are usually imposed to regulate commercial wrongdoing. ${ }^{84}$ They aim to deter without having the stigma of a criminal offence attached to them. ${ }^{85}$ The imposition of civil penalties on officers may, however, come with a certain stigma attached on the officer's professional reputation. ${ }^{86}$

One possible downside of imposing civil penalties is the power imbalance between the state and the individual. Given that these penalties are imposed and enforced by the state to further a public good, regulatees face the full force of the state enforcement machinery without the safeguards that accompany judicial criminal processes. ${ }^{87}$

At the moment, there are no civil penalties available for the breach of the due diligence duties, and no such penalties are being considered for the regulation of the due diligence duties in the HSWA at the moment. While civil penalties would add another layer of accountability on officers, the implementation of such a regime would add yet another layer of regulation the purpose of which is already served by the criminal offences of the HSWA.

Moving up the pyramid, the imposition of criminal penalties under the HSWA comes next. ${ }^{88}$ It is an offence under s 47 of the HSWA for an officer to, without reasonable excuse, "engage in conduct that exposes any individual [to whom the officer owes a duty] to a risk of death or serious injury or serious illness ... and is reckless [in that regard]". ${ }^{89}$ The officer owes the duty to the same person that

80 Sections $136-140$

81 Section 101.

82 Section 105

83 Section 123.

84 Law Commission Pecuniary Penalties: Guidance for Legislative Design (NZLC R133, 2014) at [3.1].

85 At [4.7]-[4.9].

86 At [4.24]-[4.25].

87 At [4.11]-[4.12].

88 Sections $47-49$.

89 Section 47(1)(b) and (c). See Nadia Dabee "The Due Diligence Duties in the Health and Safety at Work Act 2015" NZULR (forthcoming). 
the PCBU owes a duty to. ${ }^{90} \mathrm{~A}$ breach of s 47 makes the officer liable to a fine of up to $\$ 600,000$ or a term of imprisonment of up to five years, or both. ${ }^{91}$ Under s 48 , it is an offence for an officer to fail to comply with their due diligence duties, thereby exposing any individual to risk of death or serious injury or serious illness. ${ }^{92}$ A breach of s 48 can result in a fine of up to $\$ 300,000 .{ }^{93}$ Section 49 says it an offence for an officer to fail to comply with their due diligence duties. ${ }^{94}$ A breach can lead to a fine of up to $\$ 100,000 .^{95}$

The ultimate step in the pyramid is complete incapacitation. For a professional, the revocation of that licence is akin to "capital punishment" resulting in the full incapacitation of the regulatee. Governments may delegate authority to private parties to issues licences, such as medical licences or a licence to trade in securities. ${ }^{96}$ The state granting a professional body the right to issue licences (for example, to the Law Society) assumes that that the body will self-regulate effectively.

While there is currently no licence qualification regime in place for officers in New Zealand, there are "capital punishments" that can be imposed on directors. For example, in New Zealand, the Companies Act 1993 disqualifies certain persons from being a director. ${ }^{97}$ A person who has a "banning order" placed on them under the Employment Relations Act 2000 is disqualified from being a director. ${ }^{98}$ A banning order may be placed on a person by the Employment Court if the person persists in breaching the Employment Relations Act or employment standards. ${ }^{99}$

A similar type of restriction might be added to the HSWA. For instance, an officer who is in persistent breach of their due diligence duties could be barred from being an officer. A person who is barred under the HSWA could then also be disqualified from becoming a director under the Companies Act. However, for this disqualification to be able to operate in practice, WorkSafe will have to have consistently engaged with officers to ascertain persistent breaches for itself and thus

90 Section $47(2)$

91 Section 47(3)(b).

92 Section 48(1)(a), (b) and (c).

93 Section 48(2)(b).

94 Section 49(1)(a) and (b).

95 Section 49(2)(b).

96 Peter Grabosky "Meta-Regulation" in Peter Drahos (ed) Regulatory Theory: Foundations and Applications (ANU Press, Australia, 2017) 149 at 152.

97 Companies Act 1993, s 151.

98 Employment Relations Act 2000, s 142M; and Companies Act, s 151(2)(eab).

99 Employment Relations Act, s 142M (1)(b). 
collect evidence. WorkSafe may have the ability to obtain evidence in other ways, such as through sworn affidavits from colleagues, and to present that evidence to the District Court.

So, while at least in theory there exists the possibility of a severe punishment that would motivate compliance at the bottom of the pyramid, there appears to be very little activity to encourage compliance at the base of the pyramid. The rest of this article attempts to examine the literature to provide suggestions to improve compliance measures at the base of the pyramid.

\section{Criticisms of Responsive Regulation}

This section examines the criticisms of responsive regulation to uncover where the weaknesses of the current regulatory system are. Robert Baldwin and Julia Black have summarised the main criticisms levelled against responsive regulation. ${ }^{100}$ The first is that "step by step escalation" may not be possible after a catastrophic event. The regulator would then have to immediately deploy the "big guns". ${ }^{101}$ Another challenge is de-escalation after a tough regulator response. The relationship may have soured when the regulator had to previously escalate its response. ${ }^{102}$ Yet another issue is having the overarching threat of punishment standing in the way of voluntary compliance.

Some doubt also exists that the crux of responsive regulation, the ability to escalate in a "tit for tat" manner, actually occurs in practice. ${ }^{103}$ The limited number of interactions between the regulatee and the regulator also reduces the efficacy of the pyramid approach. ${ }^{104}$ The regulator is constrained by its own "resources, tools, cultures and practices" and the "institutional environment". ${ }^{105}$ The number of inspections of PCBUs is already low, ${ }^{106}$ which leaves one to wonder how much time the regulator has to develop a tit for tat strategy for interacting with officers. The fear of political backlash and a lack of support from the judiciary or the community may also mean the regulator may be reluctant to escalate beyond compliance. ${ }^{107}$

100 Robert Baldwin and Julia Black "Really Responsive Regulation" (2008) 71 MLR 59 at 62-64.

101 At 62 .

102 At 63. However, this a weakness acknowledged by Ayres and Braithwaite, above n 55 .

103 Vibeke Lehmann Nielsen and Christine Parker "Testing responsive regulation in regulatory enforcement" (2009) 3 Regulation \& Governance 376.

104 Baldwin and Black, above n 100, at 64.

105 At 64.

106 See above n 54 and associated text.

107 Baldwin and Black, above n 100, at 64. See Part III(F)(2) below. 
Moreover, the tit for tat escalation envisaged by Ayres and Braithwaite is complicated by the fact that regulatees' behaviour is driven by factors other than the regulator's actions. ${ }^{108}$ The dominant culture within the sector and competitive forces appear to also influence the regulatee's behaviour. ${ }^{109}$

The culture of the regulatory body is also important. A study by Jenny Job and David Honaker found that staff at the Australian Taxation Office required ongoing coaching to implement the responsive regulation method appropriately. ${ }^{110}$ Staff found it hard to switch from compliance to enforcement mode under the responsive regulation model, and shift from the previous regulatory methods of enforcing the rules through audits to the current method of escalating their response. ${ }^{111}$ Therefore the regulator must take care of setting the right tone within their own organisation first.

There is also the possibility that inspectors will not be able to escalate smoothly, either wishing to punish but not doing so because of insufficient evidence for a prosecution, or not wanting to punish but feeling compelled to do so. ${ }^{112}$ Unintended consequences of punitive behaviour by inspectors when the latter could not communicate their intentions to continue engaging positively could often result. ${ }^{113}$

Regulatees tended to focus more on negative signalling from the inspector and were quick to forget previous positive interactions. ${ }^{114}$ Following an escalation, some regulatees reacted by complaining about the inspector's behaviour under official channels, or by becoming defensive towards inspectors in subsequent interactions. ${ }^{115}$ A lack of trust in the regulator could also follow. ${ }^{116}$

108 At 63 .

109 At 63 .

110 Jenny Job and David Honaker "Short-term Experience with Responsive Regulation in the Australian Taxation Office" in Valarie Braithwaite (ed) Taxing Democracy: Understanding Tax Avoidance and Evasion (Routledge, Abingdon-on-Thames (UK), 2003) 111 at 118-125. The authors interviewed 46 officers from 22 branches of the Australian Tax Office between December 1998 and July 1999 on their experiences of responsive regulation at the point when there was a shift towards more customer service while maintaining compliance.

111 At 121 .

112 Peter Mascini and Eelco Van Wijk "Responsive regulation at the Dutch Food and Consumer Product Safety Authority: An empirical assessment of the assumptions underlying the theory" (2009) 3 Regulation \& Governance 27 at 30 and $37-39$.

113 At 30 and $39-41$.

114 At 40 .

115 At 40.

116 See generally Fiona Haines Corporate Regulation: Beyond Punish Or Persuade (Clarendon Press, Oxford, 1997). 
The increased use of responsive regulation (and its variants) by the state has also been viewed as being in line with an increase in neo-liberalisation, ${ }^{117}$ and thus with an increased decentring of the state. That is not to say that responsive regulation is the same as a neo-liberal laissez-faire approach and should be abandoned, but rather that the trend towards neo-liberalism in the regulation of WHS should be resisted. WHS is an important social "good" and a lack of regulation could lead to a regulatory failure, ${ }^{118}$ which would lead to an increase in workplace accidents.

The tendency of the state to withdraw by having less regulatory enforcement contributes to the neo-liberalist trend. ${ }^{119}$ Weak unions contribute to this trend also. ${ }^{120}$ A regulatory system that tries to resist the neo-liberal trend may be one that needs more accountability, as discussed below in Part IV.

That is not to say the state should wield a big stick over officers and punish the smallest breach. Rather, mechanisms to improve self-regulation, that is to remove the tendency towards self-interest, should be sought. Some of these mechanisms are explored below.

\section{Risk-Based Model}

The trend towards risk-based regulation can perhaps be attributed to Ayres and Braithwaite when they suggested that: ${ }^{121}$

... a fundamental principle for the allocation of scarce regulatory resources ought to be ... directed away from companies with demonstrably effective self-regulatory systems and concentrated on companies that play fast and loose.

That is not to say that risk-based regulation and responsive regulation are the same, but that there are "logical compatibilities" between the two. ${ }^{122}$

Risk-based regulation can refer to a broad range of approaches. ${ }^{123}$ At the very least, it can refer to the "use of technical risk-based tools, emerging out of economics (cost-benefit approaches), and science (risk assessment techniques)". ${ }^{124}$

117 Tombs and Whyte, above $\mathrm{n} 22$, at 47-50.

118 Feaver and Sheehy, above n 32, at 993.

119 Tombs and Whyte, above n 22, at 47-50.

120 At 50 .

121 Ayres and Braithwaite, above n 55, at 129.

122 Tombs and Whyte, above n 25, at 63.

123 Bridget M Hutter The Attractions of Risk-Based Regulation: Accounting for the Emergence of Risk Ideas in Regulation (ESRC Centre for Analysis of Risk and Regulation, Discussion Paper No 33, March 2005) at 3.

124 At 3 (emphasis omitted). 
Lizz Bluff and Richard Johnstone argue that approved codes of practice are a "modified version of risk management principles [that is] applied more widely in business". ${ }^{125}$ Both the "reasonably practicable" test and risk management strategies require the duty-holder to weigh up risks against the possible control measures of "elimination, redesign, substitution, isolation" by giving preference to "engineering means" over administrative protocols. ${ }^{126}$

The method of weighing risk against costs also aligns with the current reasonably practicable test in the HSWA. ${ }^{127}$ Bridget Hutter describes this as an "ideal" type where "risk is analysed, controlled, communicated and monitored". ${ }^{128}$ It is also a model based on certain industries' (for example, chemicals manufacturing) methodologies. ${ }^{129}$ Thus, risk-based tools may appeal to businesses as they appear to be an efficient and scientific way to allocate resources. ${ }^{130}$

\section{E Criticisms of Risk-Based Regulation}

There are some downsides to risk-based regulation. Black argues that the shift to risk-based regulation translates to how regulators and other agencies may "focus" their resources and which types of failures are tolerable. ${ }^{131}$ Risk-based regulation requires entities to know where the risks are. Organisations focus on known risks and potentially lose sight of emerging risks. The organisation that does not know what these new emerging risks are will not be able to collect the data relevant to managing those new risks. ${ }^{132}$ Black also claims that the regulator, by defining the risk-based framework, is also defining its own parameters for success and thus of accountability and responsibility. ${ }^{133}$

125 See for example some Approved Codes of Practice (ACOPs): WorkSafe New Zealand Ventilation in Underground Mines and Tunnels (Approved Code of Practice, February 2014); WorkSafe New Zealand Management and Removal of Asbestos (Approved Code of Practice, December 2016); Department of Labour Approved Code of Practice for the Management of Noise in the Workplace (October 2002); and Liz Bluff and Richard Johnstone The Relationship Between 'Reasonably Practicable' and Risk Management Regulation (National Research Centre for OHS, Australia, Working Paper 27, September 2004) at 4.

126 At 4 .

127 Section 22 .

128 Hutter, above n 123 , at 2.

129 At 2.

130 At $2-3$

131 Julia Black "The emergence of risk-based regulation and the new public risk management in the United Kingdom" [2005] PL 510 at 511.

132 At 511 .

133 At 512 and 518-519. 
There can be practical problems too. ${ }^{134}$ The application of the risk calculus can result in type-I errors (a false negative, where something is deemed to be risky when it is not) or type-II errors (a false positive, that is assuming something is not risky when it is). ${ }^{135}$ The former would favour workers, the latter would favour employers and the owners of capital. ${ }^{136}$

Hutton argues that, given a lack of hard evidence on the regulatory framework used by the regulator, one can examine the language regulators use "to frame their activities in terms of risk". ${ }^{137}$ WorkSafe states in its Regulatory Function Policy that it will target its regulatory activity "through intelligence-led analysis of risk of serious harm and/or fatalities". ${ }^{138}$ It also states that working with high-risk sectors is a matter of priority. ${ }^{139}$ Indeed, WorkSafe bases part of its success on the number of fatalities and non-fatal work related accidents (presumably an indirect measure of the risk of dying or of being injured at work). ${ }^{140}$ While hiding fatalities at work may be hard, it is possible that workrelated injuries are under-reported. ${ }^{141}$ Moreover, focussing on these figures may not give us a true picture of the state of WHS culture in New Zealand. ${ }^{142}$

Such targeted "responsive inspections" have been criticised as being a dilution of a pure responsive regulation regime, bringing the level of inspections to a low level never envisaged by Ayres and Braithwaite. ${ }^{143}$ Tombs and Whyte opine that justifying lower, but targeted, inspections

134 At 517.

135 At 517

136 At $517-518$

137 Hutter, above n 123, at 4

138 WorkSafe New Zealand, above n 25, at 5.

139 At 36.

140 At 19.

141 See for example Glenn Pransky and others "Under-reporting of work-related disorders in the workplace: a case study and review of the literature" (1999) 42 Ergonomics 171 (workers disclosed they were not reporting workplace injuries due to fear of reprisals, beliefs that pain was part of work, management unresponsiveness to complaints and fear of job loss or demotion); Alan Hall "Trust, uncertainty and the reporting of workplace hazards and injuries" (2016) 18 Health, Risk \& Society 427 (temporary workers are more likely to be fearful of reporting workplace injuries); Price V Fishback and Shawn Everett Kantor "The Adoption of Workers' Compensation in the United Sates, 1900-1930" (1998) 41 Journal of Law and Economics 305 at 315, n 25 (death rates have been described as a measure "with the fewest reporting error[s]"); and James R Chelius "Liability for Industrial Accidents: A Comparison of Negligence and Strict Liability Systems" (1976) JLS 293 at 301-306 (death rates were used as the most accurate measure of the effect of employer liability laws).

142 Safety culture is usually measured through organisational surveys. See for example AI Glendon and NA Stanton "Perspectives on safety culture" (2000) 34 Safety Science 193.

143 Tombs and Whyte, above n 22, at 66. 
rates under the guise of responsive risk-based regulation is a way of deregulating WHS. ${ }^{144}$ The authors also showed that deregulation leads to increased workplace accidents and illnesses. ${ }^{145}$

Also, risk-based regulation can easily become static, in that it assumes that the probability of an adverse event occurring is almost always the same. ${ }^{146}$ This assumption is of course untrue; there are too many confounding factors that can contribute to the determination of risk. WorkSafe reported that it has a system in place to spot emerging risks. ${ }^{147}$ This is at least an attempt to avoid stasis. However, emerging risks may be tackled more effectively by using safety-II techniques.

\section{F Overcoming the Problems Associated with Traditional Risk-Based Regulation}

In a nutshell, Safety-I is the more traditional view of safety where hazards and risks are first identified, and workers follow set processes to prevent accidents. ${ }^{148}$ The causes of accidents are viewed as being linear and often the consequence of the process not being followed. ${ }^{149}$

Safety-II views safety as "things going right" and tries to understand the conditions under which work can be carried out successfully in order to be able to react to avoid an accident when things do "go wrong". ${ }^{150}$ Safety-I and Safety-II can, and should, co-exist with one other. ${ }^{151}$ Most activities in the workplace can be managed using Safety-I processes, ${ }^{152}$ with certain situations requiring a SafetyII approach. ${ }^{153}$

144 At 66.

145 At 61. As the number of inspections fell in the United Kingdom over a period of 10 years, the number of serious accidents investigated and prosecuted also fell, as did the number of prohibition and improvement notices issued.

146 Black, above n 131, at 519.

147 WorkSafe New Zealand, above n 25, at 36.

148 Hollnagel, above n 41, at 42.

149 At 42 .

150 At $134-142$

151 At ch 8 .

152 At 148

153 At 148 
Safety-II is a scientific method to manage risks that derives from the engineering concept of "resiliency". ${ }^{154}$ Processes can, and should be adapted to the situation and changed as the situation changes. ${ }^{155}$ The organisation can adapt by managing its resilience potentials, that is its ability to: ${ }^{156}$

- respond to regular and irregular changes in work patterns;

- monitor and know what it needs to look for;

- learn the right lessons from past experiences; and

- anticipate, or know what to expect in the future.

The philosophy of Safety-II is for employers to accept that workers do make "sensible" changes to accepted work protocols in order to get the job done. ${ }^{157}$ Thus, implementing Safety-II principles allows the business to respond dynamically to risks and variations in tasks and overcome the "stasis" in the more traditional risk management.

The main problem with Safety-II is building the organisation's capacity to manage its resilience potentials. The technique involves mapping out the different resilience potentials and thinking about their interactions, an activity that requires a skilled person. Moreover, Safety-II does accept that accidents will occur, but that organisations need to figure out why the adaptions made by workers to working practices resulted in an accident. This is a time and resource intensive process, not one which businesses already facing constraints can easily engage with.

That being said, a regulatory system that incorporates safety-II techniques may be able to overcome the stasis associated with the current risk-based regulatory regime which is based on more traditional approaches to safety management.

There would still be a traditional enforcement pyramid for Safety-I processes. Alongside this, WorkSafe would ensure that the PCBU is indeed managing its resilience potentials well for Safety-II processes. WorkSafe would also provide advice when needed (thus there would be no escalation up the pyramid, hence a rectangle to represent the regulatory activity for Safety-II). ${ }^{158}$ Whether the PCBU is following a Safety-I or a Safety-II process, WorkSafe will still prosecute when there is a serious breach of duty or a serious accident. In both circumstances, WorkSafe will still have the ability to decide, depending on the seriousness of the offending, whether to accept an enforceable

154 See generally Ondrej Bastan, Tomas Benesl and Petr Fielder "Resiliency, the Path to Safety II" (2018) 51 IFAC-PapersOnLine 468

155 Hollnagel, above n 41, at 126-127.

156 At $126-127$.

157 At 149 .

158 See Hollnagel, above n 41, at ch 5 for a description of how to monitor and improve resilience potentials. 
undertaking or to prosecute for a s 47 offence under the HSWA which carries a possible term of imprisonment of up to five years. ${ }^{159}$

Figure 2: Suggested Diagrammatic Representation of Enforcement of WHS duties for a PCBU that is using Safety-II as well as Safety-I.

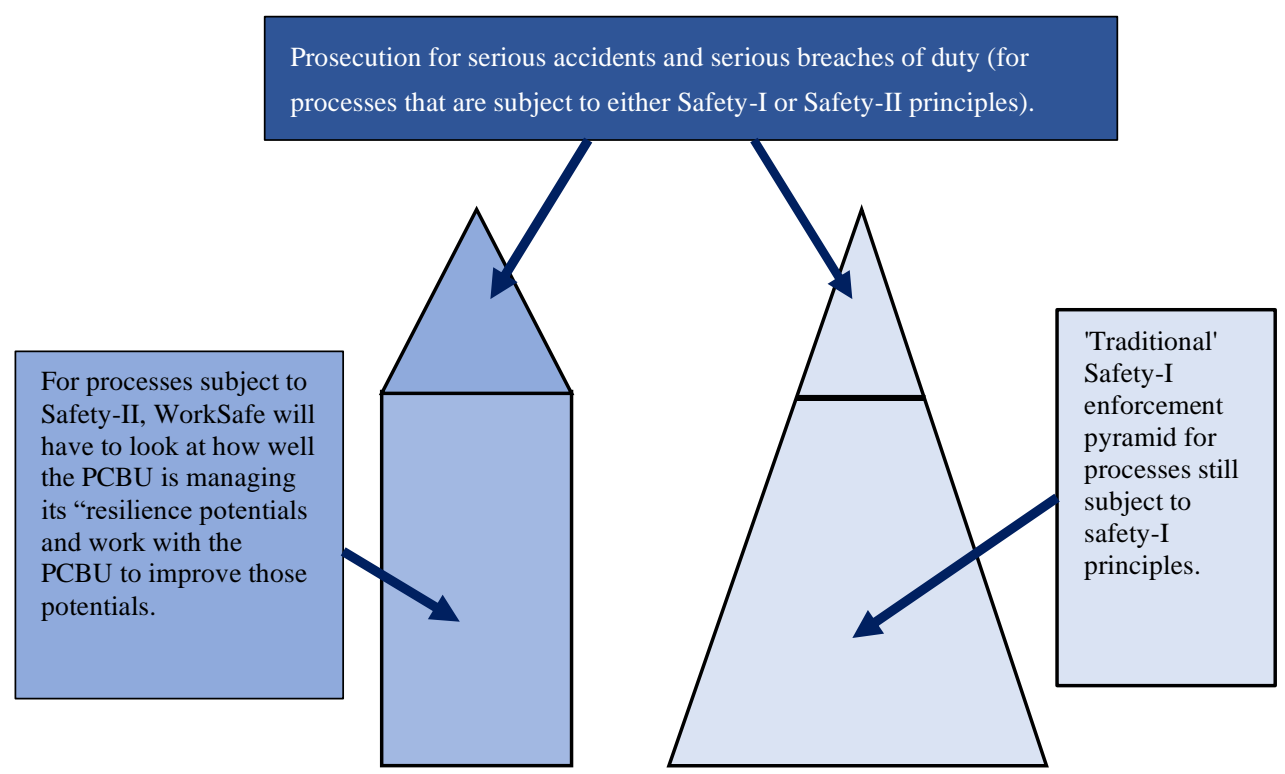

Not all activities can be subject to Safety-II principles. The regulator will need to reflect on which type of safety principles it is regulating when dealing with the regulatee. This, of course, adds another burden on the regulator.

\section{G Self-Regulation}

\section{Definition of self-regulation}

Self-regulation can have various meanings in different contexts. Black says "[w]hatever 'selfregulation' is, it is not state regulation; it must therefore have a natural place in the new 'decentred' regulatory world" ${ }^{160}$ Self-regulation, in its simplest and purest form, refers to individual associations

159 Section 123.

160 Black, above n 33, at 113 . 
and organisations regulating themselves. Neil Gunningham explains that pure self-regulation, or a complete absence of the state, and pure state intervention, rarely exist in the "real world". ${ }^{161}$

Black refers to "mandated" self-regulation where a group or organisation are required by the government to "formulate and enforce norms" within a set framework. ${ }^{162}$ "Sanctioned" self-regulation is where groups formulate their rules subject to government approval. ${ }^{163}$ "Coerced" self-regulation is where the industry formulates and imposes rules as a result of a direct threat from the government to impose statutory regulation otherwise. ${ }^{164}$ "Voluntary" self-regulation is where there no active state involvement but the groups decides to self-regulate. ${ }^{165}$

Self-regulation can exist under the responsive regulation model, where most of the compliance is at the base of the pyramid is voluntary. ${ }^{166}$ Thus self-regulation has been associated with the threat of moving up the enforcement pyramid when there is a lack of compliance. ${ }^{167}$ The sub-Parts below on co-regulation and meta-regulation refer to self-regulation within the regulatory pyramid. ${ }^{168}$

\section{Strengths and weaknesses of "pure" self-regulation}

A strength of self-regulation is being seen as a type of regulation that is "responsive, flexible, informed, targeted" and that achieves greater compliance. ${ }^{169}$ Practitioners are deemed to have more knowledge of their industry, and thus able to develop more "practicable standards". ${ }^{170}$ Self-regulation may involve "ethical standards of conduct" and thus this type of regulation may raise the standards of conduct in the industry. ${ }^{171}$

161 Neil Gunningham Investigation of Industry Self-Regulation in Workplace Health and Safety in New Zealand (June 2011) at 8.

162 Julia Black "Constitutionalising Self-Regulation" (1996) 59 MLR 24 at 27.

163 At 27.

164 At 27.

165 At 27 .

166 Ayres and Braithwaite, above n 55, at 6.

167 Black, above n 33, at 113.

168 Meta-regulation, co-regulation and enforced co-regulation are all variants of self-regulation and are discussed further below.

169 Black, above n 33, at 115.

170 Neil Gunningham "Environment, Self-Regulation, and the Chemical Industry: Assessing Responsible Care" (1995) 17 Law \& Pol'y 57 at 58

171 At 58 . 
A possible weakness however is that the regulatory community becomes "self-serving and selfinterested" and that there is a lack of sanctions, and there will always be "free riders". ${ }^{172}$ The use of self-regulation can lead to the regulatee perception that the government is not taking the problem to be regulated seriously. ${ }^{173}$ Self-regulation has even been described as a "sham" or as a "cynical attempt by self-interested parties to give the appearance of regulation". ${ }^{174}$

Gunningham suggests that "bitter experience" has shown that industry co-regulation is more appropriate than pure self-regulation and suggests co-regulation may be able to take advantage of the benefits of pure self-regulation while overcoming its shortcomings. ${ }^{175}$ This is discussed further below.

\section{Possible solutions to the problems posed by self-regulation}

As it appears that officers have been mostly left to regulate themselves in New Zealand, the search for a better solution first points to the regulatory solutions that may overcome the problems caused by self-regulation. The two possibilities presented here are co-regulation and meta-regulation.

(a) Co-regulation and enforced co-regulation

Co-regulation is often seen as a sub-set of self-regulation, ${ }^{176}$ and can be an answer to the perceived burdens of imposing detailed government regulation. ${ }^{177}$ Black explains that co-regulation "refers to a degree of legislative underpinning of codes or standards" that is the "legislative delegation of power to industry to regulate and enforce codes" with the "back-stop" of legislation to enforce the codes. ${ }^{178}$

Csnik and Mayer have defined co-regulation as: ${ }^{179}$

... situations where the regulation required by law is delegated to an industrial - or even self-regulatedbody. The codes of behaviour are accepted by professionals and state regulatory bodies as the result of cooperation.

172 Black, above n 33, at 115 .

173 At 115 .

174 Gunningham, above n 170, at 58 .

175 Gunningham, above n 161, at 4 .

176 See Lóránt Csnik and Annamária Mayer "How to Regulate: The Role of Self-Regulation and Co-Regulation" (2014) Hungarian Yearbook of International Law 403 at 405; and Black, above n 33, at 117.

177 John Braithwaite "Enforced Self-Regulation: A New Strategy for Corporate Crime Control" (1982) 80 Mich L Rev 1466 at 1471 .

178 Black, above n 33, at 117.

179 Csnik and Mayer, above n 176, at 471. 
The rules should at least meet statutory minima. ${ }^{180}$ If the regulatory body does not approve of the codes, it may send it back for revision. ${ }^{181}$ Community groups could be invited to comment on the codes and rules. ${ }^{182}$ The violation of approved rules would be punishable by law. ${ }^{183}$

Large organisations could appoint internal regulators, who could also act as a safety representative. ${ }^{184}$ Consortiums of small and medium-sized businesses could also appoint regional safety representatives as internal regulators for their group. Existing trade associations could form these consortiums. ${ }^{185}$ Further, each consortium could have several officers' associations to share their knowledge and offer peer support.

Extending the role of safety representatives and forming consortiums to help regulate officers' conduct may be seen as a threat by management. Indeed, it is possible to foresee industrial disputes spinning out of control if safety representatives use their powers to coerce officers into giving in to workers' demands. In order to avoid the possibility of such "face-offs", internal regulators should not have punitive powers, as WorkSafe does. The incentive for officers to work collaboratively with internal regulators is the avoidance of WorkSafe's intervention.

The internal regulators will need some powers to carry out their work. They should have the statutory power to inspect workplaces and issue improvement notices, if necessary, to request dutyholders to comply. ${ }^{186}$

Finally, the internal regulators should also have expertise in their field, as well as knowledge of the strengths-based regulatory technique, and possibly an understanding of Safety-II principles. The right training may also help ensure that internal regulators do not use WHS issues to fuel industrial disputes. The hiring and training of such regulators would, of course, require funding from both the private sector or from the government. ${ }^{187}$

The internal regulator system could, in turn, be approved and overseen by WorkSafe. WorkSafe could then opt to punish those officers who break the rules by removing the right to self-regulate

180 Braithwaite, above n 177 , at 1471.

181 At 1471 .

182 At $1470-1471$.

183 At 1471 .

184 Black, above n 33, at 116.

185 At 119.

186 At 132-133. Safety Representatives already have some of these powers: see HSWA, s 69.

187 HSWA, s 201. There is already a provision in place for WorkSafe to get a funding levy from employers and self-employed persons. 
and/or imposing a fine or other penalty or reward those officers who self-regulate effectively by minimising interference and audits. ${ }^{188}$

The author of course recognises that this is an additional regulatory burden on officers. The idea is that, if officers can self-regulate effectively, the state would not interfere. Codes and rules could thus be developed for the regulation of the due diligence duties. This idea is discussed in more detail in the section on meta-regulation below.

(b) Meta-regulation

Black notes that risk-based regulation, discussed above, goes "hand in hand" with meta-regulation which focusses on an organisation's "internal controls" as a pre-requisite for the success of the regulatory regime. ${ }^{189}$ The problem with meta-regulation, as with self-regulation, is that organisations may be too focussed on their own objectives to be able to align themselves effectively with the regulator's (and thus the state's objectives). ${ }^{190}$

Meta-regulation has been described as the oversight of the regulatee's "governance mechanisms", ${ }^{191}$ or a "regulation of self-regulation", ${ }^{192}$ or the process of the state overseeing selfregulatory arrangements. ${ }^{193}$ Meta-regulation can also be seen as part of the deregulatory trend, or a search for a "regulatory state beyond the state". 194

Peter Grabosky refers to meta-regulation as a "kind of performance monitoring of regulatory institutions". ${ }^{195}$ Like pure self-regulation, the regulatee implements the regulations itself. ${ }^{196}$ The

188 Cary Coglianese and Jennifer Nash "Government Clubs: Theory and Evidence from Voluntary Environmental Programs" in Matthew Potoski and Aseem Prakash (eds) Voluntary Programs: A Club Theory Approach (The MIT Press, Cambridge (Mass), 2009) ch 11.

189 Black, above n 131, at 511.

190 At 519

191 Colin Scott "Speaking Softly Without Big Sticks: Meta-Regulation and Public Sector Audit" (2003) Law \& Pol'y 203 at 213.

192 Christine Parker The Open Corporation: Effective Self-Regulation and Democracy (Cambridge University Press, Cambridge, 2002) at 245.

193 At 245 .

194 Robert Baldwin, Martin Cave and Martin Lodge "The Future of Regulation" in The Oxford Handbook of Regulation (Oxford University Press, Oxford, 2010) 613 at 618.

195 Grabosky, above n 96, at 149.

196 Folarin Akinbami "Is meta-regulation all it's cracked up to be? The Case of UK Financial Regulation" (2013) 14 JBR 16 at 18 
regulator harnesses the regulatee's control mechanisms and poses the threat of a punishment or the lure of a reward (which can be a lack of intervention by the state). ${ }^{197}$

Grabosky further observes that meta-regulation can refer to "activities occurring in a wider regulatory space", involving the state, the private sector and public interest groups. ${ }^{198}$ At one extreme, governments would be "passive observer[s]", and "non-state institutions" would perform most of the regulatory functions. ${ }^{199}$ The other extreme would involve the state being an "active director" commanding, by law, private actors to assist in the regulatory process. ${ }^{200}$ For instance, officers' ability to design their own compliance model should, in theory, allow officers to stick to the "spirit" of the law, rather than to engage in "box ticking" exercises. ${ }^{201}$

An application of meta-regulation to the due diligence duties could involve officers designing a system to regulate their behaviour in keeping with the spirit of the law, either within a firm, or across organisations. The behaviour of officers could then, for example, be held to account by an independent board that would comprise of community members (for example unions, workers, industry experts, consumers and so on).

Oversight by an independent board may overcome the problem of regulatees focussing on their own self-interest which would eventually lead to regulatory failure. For example, Folarin Akinbami has argued that the banking crisis was partly due to the fact that the finance sector was motivated by greed and self-interest, and thus, it was wrong for the regulator to assume the sector would behave responsibly if given the opportunity and that some form of regulatory oversight should have taken place. ${ }^{202}$

In particular, Black talks about self-regulated associations (SRAs) which "combine the governmental function of regulation with the institutional and often legal structure and interests of a private body". ${ }^{203}$ SRAs can link different parts of society in a "horizontal manner", ${ }^{204}$ without the necessarily placing the state at the apex of the hierarchy. SRAs can also help develop and further public policy. ${ }^{205}$ These SRA-type of structures could usefully form part of the regulatory framework

197 At 18.

198 Grabosky, above n 96, at 150.

199 At 153.

200 At 152.

201 Akinbami, above n 196, at 19.

202 At 20.

203 Black, above n 162, at 28.

204 At 29.

205 At 28. 
surrounding the due diligence duties in the form of the consortiums discussed above. The SRAs would work at the base of the regulatory pyramid (see Figure 1 above), at the persuasion stage.

Indeed, diverse groups, such as markets, the community, the state and associations, working together to keep each other in check was also an idea put forward by Ayres and Braithwaite. ${ }^{206}$ The basis upon which the authors advocate "transcending" the "regulation versus deregulation" debate is based on promoting the participation of community and other interest groups. ${ }^{207}$

FC Simon further states that, by leveraging the moral values of the regulated community, metaregulation aims to bring the moral values of the regulated community in line with public interest. ${ }^{208}$ She argues that, while meta-regulation is usually viewed by policy makers as progressive, being able to meet the public interest through the involvement of stakeholders, those claims may not eventuate in practice. ${ }^{209}$

The regulator would thus have to formulate the "public interest goal" that is being sought through the regulation of officers' duties. ${ }^{210}$ Each PCBU, or group of PCBUs, would then have to develop a plan to improve WHS culture. ${ }^{211}$ WorkSafe would then monitor the plans to determine if they were acceptable.

However, the main problem appears to be the conflict among the stakeholders that are meant to make the system work. ${ }^{212}$ Therefore, a successful application of meta-regulation to the due diligence duties would depend on whether officers within a particular industry and WorkSafe can agree on the normative values that should be upheld. A possible conflict could be officers preferring to prioritise efficiency in processes, and WorkSafe emphasising that time be spent on proper communication with employees and other workers. Indeed, the success of meta-regulation appears to depend on the complexity of the issue and the "degree of ... conflict over values..."213

206 Ayres and Braithwaite, above n 55, at 16.

207 At 17 .

208 FC Simon Meta-Regulation in Practice: Beyond Normative Views of Morality and Rationality (Routledge, Abingdon-on-Thames (UK), 2017) at 18

209 At 18.

210 Akinbami, above n 196, at 18.

211 Cary Coglianese and Evan Mendelson "Meta-Regulation and Self-Regulation" (2010) in Robert Baldwin, Martin Cave and Martin Lodge (eds) The Oxford Handbook of Regulation (Oxford University Press, Oxford, 2010) 146 at $146-168$.

212 Simon, above n 208, at 235.

213 Neal Woods "The Limitations of Meta-Regulation in Practice: Beyond Normative Views of Morality and Rationality (book review)" (2019) 29 Journal of Public Administration Research and Theory 152 at 154. 
Malignant political intentions of stakeholders can corrupt the otherwise well-intentioned intended outcome of improving behaviour. ${ }^{214}$ Thus, in the WHS context, a rogue officer, or a rogue union representative can easily throw the whole regulatory system off kilter.

The regulator is not exempt from political influences either. Pressure to act with a "light touch", either from stakeholders or the government, can lead to regulatory failure. ${ }^{215}$ There is also the fact that some end users (clients or consumers) may not care about compliance, ${ }^{216}$ and can do very little to change officers' behaviour.

Moreover, the assumption, normally absent in practice, is that the regulator is able to create a type of "value consensus" among the members of the regulated community, and that regulators and regulatees are "rational". ${ }^{217}$ In practice, the regulator and regulatees usually form their own respective sub-unit and construct their own separate reality, thus a consensus of values and rational behaviour is difficult to achieve. ${ }^{218}$ A possible way to overcome these divisions is to leverage off the understanding that WorkSafe will not intervene as long as the officers regulate themselves effectively at the base of the pyramid.

The other precursor to success would be the willingness of all the relevant parties to communicate effectively. ${ }^{219}$ Communication should occur "between the 'right' entities about the 'right' issues on the 'right' terms at the 'right' times". ${ }^{20}$ There appears to be limited opportunity for this type of communication to occur within an organisation, let alone among a group of organisations.

\section{ACCOUNTABILITY OF THE REGULATOR}

\section{A The Accountability of WorkSafe}

Under the HSWA, the enforcement powers rest with WorkSafe. When enforcement activities go wrong, WorkSafe then "bears the brunt of any accountability". ${ }^{221}$ One can speculate, of course, that, if WorkSafe were to discharge its duties in a deleterious way, public outcry might require the government to step in and perhaps overhaul the regulator.

214 Simon, above n 208, at 22.

215 Akinbami, above n 196, at 24.

216 Simon, above n 208, at 22.

217 At 18 .

218 At 18 . The use of meta-regulation in the Australian energy market failed to produce any behaviour change among energy retailers.

219 At 20.

220 At 20.

221 Feaver and Sheehy, above n 32, at 972. 
The HSWA allows a "person affected by [a decision made by WorkSafe]" to apply for a review of a decision: ${ }^{222}$

- to issue a notice;

- to cancel or vary the notice;

- to extend the time to comply with an improvement notice;

- to stay the operation of a decision to issue a notice;

- that is allowed by the regulations.

The affected person has to make an application for review the day after the notice first comes to their attention. ${ }^{223}$ A longer period to notify is possible only if allowed by the regulator. ${ }^{224}$ For an improvement notice, the affected person has the lesser of the duration of the improvement notice or 14 days to apply for an internal review. ${ }^{225}$ The regulator must respond "as soon as practicable" within 14 days after receiving the application. ${ }^{226}$ The decision may be to confirm, vary, or set aside the decision, or substitute with another decision. ${ }^{227}$ The application must then be made aware of the decision that WorkSafe made on the internal review. ${ }^{228}$

WorkSafe aims to "demonstrate consistency, accountability and transparency" and be able to "withstand scrutiny". 229 The regulator also appears to have taken up natural justice principles, such as quick resolution of appeals and having reviewers acting "independently and in good faith and for a proper purpose". ${ }^{230}$ It also aims to keep applicants informed of the outcomes of the reviews and provide reasons for decisions. ${ }^{231}$ WorkSafe is in a sense reviewing its own decisions. Only "unreasonable" decisions can then further be appealed within 14 days to the District Court. ${ }^{232}$

The case of Osborne $v$ WorkSafe New Zealand was appealed all the way to the Supreme Court on the grounds that WorkSafe had decided not to prosecute the directors of the Pike River Mine in

222 Section 130 definition of "eligible person".

223 Section 131(1).

224 Section 131(1).

225 Section 131(3).

226 Section 132(1).

227 Section 132(3).

228 Section 133.

229 WorkSafe New Zealand Reviews (October 2016) at 1.

230 At 2.

231 At 2.

232 HSWA, s 135(1). 
exchange for payment. ${ }^{233}$ WorkSafe had denied doing this and said it had considered other matters in line with its prosecution guidelines (such as the low prospect of success) when it reached its decision not to prosecute. ${ }^{234}$

In the end, the Supreme Court found that WorkSafe had acted illegally in dropping the charges against the director in exchange for payment. ${ }^{235}$ Much to its credit, WorkSafe appears to have accepted the Supreme Court's decision. ${ }^{236}$ Since then, other judicial review challenges have been rejected, ${ }^{237}$ suggesting (perhaps) better decision-making by WorkSafe in its enforcement policy.

\section{$B$ The Accountability of Internal Regulators}

If a self-regulatory model were used where officers were to regulate themselves, they could then be held accountable by "community stakeholders, to the regulator and possibly the courts, to the markets or other interest groups". 238

Braithwaite suggests the use of industry inspectors who would perform the "primary function[s]" of government inspectors, but that "old-style direct government monitoring" would still be necessary for organisations that are too small to afford their own inspectors. ${ }^{239}$ While Braithwaite may be right on the latter point, WorkSafe would hardly have the resources necessary to effectively build ongoing relationships with all small businesses in New Zealand.

However, Braithwaite also notes that, while private regulatees may be more capable than the government of regulating their own activities, they may not always be willing to do so. ${ }^{240}$ The main reason for this reluctance is cost. If reporting the violation saves the company money in the short or long term, they may be more willing to report it, but would otherwise prefer to ignore any breaches. ${ }^{241}$

The solution presented above of using internal regulators and consortiums may help to increase regulatory capacity and thus to have more oversight of compliance of the due diligence duties. The

233 Osborne v WorkSafe New Zealand [2017] NZSC 175, [2018] 1 NZLR 447 at [10] and [77].

234 At [17].

235 At [95], [101] and [102].

236 WorkSafe New Zealand "Supreme Court decision - Rockhouse/Osborne v WorkSafe New Zealand" (23 November 2017) <https://worksafe.govt.nz>.

237 See for example Talley's Group Ltd v WorkSafe New Zealand [2018] NZHC 1565, (2018) 16 NZELR 162 at [10]; and Off Road New Zealand (1992) Ltd v Machinery Inspector [2019] NZHC 1996 at [73].

238 Feaver and Sheehy, above n 32, at 972.

239 Braithwaite, above n 177, at 1471.

240 At 1469.

241 At 1469. 
internal regulators would work at the base of the regulatory pyramid, and "pass the baton" to WorkSafe for either repeated breaches or serious wrongdoing.

Braithwaite thus suggests a mandatory reporting regime, with a failure to report being a punishable criminal offence. ${ }^{242}$ Industry inspectors may have a greater ability to "trap suspected wrongdoers" than state inspectors. ${ }^{243}$ In an enforced co-regulatory model, Braithwaite suggests that regulatees be "required to report to the relevant regulatory agency any management overruling of compliance group directives". ${ }^{244}$ He suggests that a failure to report should be criminally punishable.

Thus, the internal regulator system suggested above should also have a mandatory duty to report repeated or severe non-compliance. ${ }^{245}$ The internal regulators should be criminally liable, by paying a fine, for failing to report. Both the internal regulator and officers will then know that internal regulators have no choice but to report. Officers should be criminally liable, by paying a fine, for discouraging an internal regulator from reporting so that they are less likely to suppress an internal regulator from reporting. ${ }^{246}$ The law should also make it clear that false reporting, or using the threat of reporting when there is no reason to report, will also be criminally punished with a fine. This will avoid vexatious use of the internal regulator's powers.

Black takes things further and looks at the possibility of judicial reviews for SRAs. She finds that it may not be appropriate to judicially review the powers of an SRA as they are not in the public sphere. ${ }^{247}$ Nonetheless, the decisions made by these groups do have a significant influence on public well-being and should thus be amenable to review and the groups held to account. ${ }^{248}$ Black then concludes that this modified version of judicial review is appropriate given the private/public nature of these SRAs. ${ }^{249}$ The key, Black argues, is to understand SRAs as mediating between different autopoietic systems rather than between the state and individuals. ${ }^{250}$ Thus a different form of judicial review that looks at whether the processes of the SRA achieved its aims may become possible. ${ }^{251}$

\section{At 1470.}

243 At 1469.

244 At 1470.

245 Ayres and Braithwaite, above n 55, at 118-119.

246 At $118-119$.

247 Black, above n 162, at 29.

248 At 29.

249 At 43 .

250 At 51

251 At 52 . 
Courts would, however, have to gain a knowledge of the inner workings of the SRA. ${ }^{252}$ The courts could then direct how SRAs should be structured and how decision-making processes should occur. ${ }^{253}$ The focus would be to review structures and processes, not to impose a particular outcome. ${ }^{254}$

To use the example given by Black, a jockey club could be asked to reformulate a discriminatory rule on the basis that all citizens should be treated equally. ${ }^{255}$ The court could require the club to consider the views of those who claim to be discriminated against. ${ }^{256}$ The same method could apply to an organisation of officers. An officer who feels they have been discriminated against by an internal regulator or by other members could request the court to review the processes and rules of the association.

\section{CONCLUSION}

The main suggestions for regulating the due diligence duties presented in this article can help both to resist neo-liberal trends and to improve regulatory capacity. While the problems associated with responsive regulation cannot be removed altogether, the inherent trend towards neo-liberalism that is present at the bottom of the pyramid can be overcome.

A possible solution would be the use of SRA-type structures where industry associations would help officers come up with compliance plans that would then be approved by WorkSafe. These associations would be able to extend regulatory capacity by devolving some responsibility for regulation on private parties. In order to maintain the accountability of those private parties and to avoid a neo-liberal spiral, a modified type of judicial review process can be used to hold the SRAtype structures accountable. There should also be duties for internal regulators to report repeated or breaches of the due diligence duties to WorkSafe. Tensions within the SRA-type structures are bound to exist, but an external committee that can review the functions of the SRA may help to smooth relationships.

The incorporation of Safety-II principles in the regulatory framework may help overcome some of the weaknesses of the current risk-based regulatory regime.

To further strengthen the current regulatory structure, the possibility of disqualifying an officer from holding such an office for persistent breaches of the HSWA should also be considered.

252 At 53.

253 At 53 .

254 At 53. This review could also help SRAs who reach an impasse on deciding what their common goals and values are.

255 At 53 .

256 At 54. 
All these changes, of course, would require considerable resources and know how. The upside would be a unique regulatory system focusing on improving the ability and willingness to act of those who are most able to make the organisational changes that would improve WHS in New Zealand. 
